\title{
Increasing breeding success of an Endangered penguin: artificial nests or culling predatory gulls?
}

\author{
LORIEN PICHEGRU
}

\begin{abstract}
Summary
Drastic recent decreases in numbers of the 'Endangered' African Penguin Spheniscus demersus highlight the need for conservation efforts to reverse this trend. Habitat reduction due to former guano scraping forces penguins to breed in surface nests, which are vulnerable to predation by Kelp Gulls Larus dominicanus and to extreme weather events. Here I compare gull predation and the success of penguins breeding in surface nests and two types of artificial nests, before (2009) and after (2010-2011), the removal of predatory gulls from Bird Island, South Africa. Both culling gulls and providing artificial nests improved penguin chick survival, but post-culling chick survival was lower in surface nests than in artificial nests, suggesting a major impact of weather on chick mortality. Success of artificial nests was design-dependent, with poor hatching success in fibreglass burrows (probably due to high ambient temperatures), but nests under $50 \mathrm{~cm}$ cement pipes cut in half had the highest breeding success. Therefore, appropriately designed artificial nests can enhance African Penguin breeding success, shielding them from both predation and extreme weather events. Where implementing such nests is constrained, controlling Kelp Gulls can also enhance penguin production, especially during years of low food availability when the vulnerability of chicks to predation is exacerbated. Such a strategy would, however, require ongoing management, as territories freed by culled gulls are constantly filled with new individuals. The alarming trend in African Penguin numbers justifies robust conservation strategies, although these should also be concomitant with limiting oil spills and increasing food availability around their colonies.
\end{abstract}

\section{Introduction}

The African Penguin Spheniscus demersus is endemic to Southern Africa but its population is currently at the lowest level ever recorded (Crawford et al. 2011). Direct exploitation by humans and reduction of suitable nesting habitat through guano exploitation for more than 150 years caused their population to decrease by $90 \%$ during the $20^{\text {th }}$ century (Crawford et al. 1995). Protection of the species in 1976 to prevent further exploitation led to some recovery in numbers (Crawford et al. 1995). However, recent decreases in food availability, due to a shift in distribution and abundance of their main prey, caused a further $60 \%$ population reduction in South Africa between 2001 and 2009 (Crawford et al. 2011). The species is now listed as 'Endangered' (BirdLife International 2011) and considerable efforts are currently being coordinated to identify the major threats impacting on African Penguins and to set objectives to address this decline - see the recently written African Penguin Biodiversity Management Plan (Waller and Shaw 2010). For example, experimental fishing exclusions have been implemented around key breeding localities to increase food availability for penguins (Pichegru et al. 2010), the small-scale variability in distribution and abundance of their main prey is being investigated 
(J. C. Coetzee unpubl. data), as well as the consequences of industrial fishing over fine scales in the vicinity of their colonies (Pichegru et al. 2012). The effects of predation and climate change on African Penguin reproductive output still remain to be addressed in the context of conservation management.

Historic guano exploitation still has an impact on penguins, as the lack of suitable substrate in which to burrow forces penguins to breed in surface nests (Figure 1a). African Penguins naturally dig burrows in guano that provide protection from aerial predators as well as providing a constant microclimate, with high relative humidity, buffered temperatures and little exposure to the wind (Frost et al. 1976). Penguins are generally sensitive to heat stress while breeding (Frost et al. 1976, Seddon and Davis 1989). If breeding adults are forced to leave their nests due to disturbance or heat stress, surface breeders are more vulnerable to predators, such as Kelp Gulls Larus dominicanus, than birds in burrows (Cooper 1974, Frost et al. 1976, Yorio and Boersma 1994).

Populations of many large gulls Larus spp. are increasing worldwide (Crawford et al. 2009, Lisnizer et al. 2011), due to cessation of control and/or increased human food subsidies, such as fisheries waste and open refuse tips (Bertellotti et al. 2001, Yorio and Caille 2004). Gulls are often considered as an overabundant pest species (Blokpoel and Spaans 1991, Yorio et al. 1998). When targeting seabirds' eggs and chicks, gulls can decrease breeding success and affect dispersal and recruitment (Harris and Wanless 1997, Finney et al. 2003, Donehower and Bird 2008). Some gulls can be highly specialised and pose a serious threat to seabird colonies (Spears 1993, Yorio and Quintana 1997). Reducing the numbers of gulls has assisted the recovery of some seabird populations (e.g. Finney et al. 2003, Sanz-Aguilar et al. 2009), but this is not invariably the case (Harris and Wanless 1997). Management decisions pertaining to "pest" species should be based on appropriate scientific evidence (Sutherland et al. 2004, Oro and Martínez-Abraín 2007), as altering predator-prey interactions in human-modified environments may have more profound impacts than anticipated (Yodzis 1998, Dickman 2008). Thus, decisions to remove predators from a system over a protracted period should be monitored extremely carefully and alternative solutions should also be considered.

To reduce Kelp Gull predation on burrowing seabirds eggs and chicks, an alternative to culling is to provide artificial nests. Such nests could also shelter penguins against extreme weather events. Indeed, small chicks raised in surface nests are also more exposed to mortality during severe rains (Randall et al. 1986, Frere et al. 1992, Renner and Davis 2001, Demongin et al. 2010). Artificial nests have proved successful in increasing breeding success of Little Penguins Eudyptes minor in New Zealand, providing shelter from predation (Perriman and Steen 2000) and potentially from rain (Renner and Davis 2001). However, similar nests failed to increase the breeding success of the same species in Australia, due to high ambient temperatures inside the nests (Ropert-Coudert et al. 2004). The success of artificial nests is therefore site- and design-dependent (Kemper et al. 2007).

In this study I compared the potential benefits of culling gulls and of implementing two types of artificial nests on the breeding success of African Penguins on Bird Island, Nelson Mandela Bay, South Africa. I compared the intensity of predation by Kelp Gulls on African Penguin nests, and breeding success of penguins in surface and artificial nests (Figure 1), one year before (2009) and two years (2010-2011) after culling. I hypothesised that (I) gull predation on penguin eggs and chicks would decrease after culling, (2) breeding success in surface nests would be lower than in artificial nests prior to gull control, and (3) this success would increase after culling gulls.

\section{Methods}

The study took place on Bird Island $\left(33^{\circ} 50^{\prime} \mathrm{S}, 26^{\circ} 17^{\prime} \mathrm{E}\right)$ between January and August, the peak of the penguin breeding season in Nelson Mandela Bay (Hockey et al. 2005) in 2009, 2010 and 2011. Bird Island currently supports $>10 \%$ of the global population of African Penguins (2,500 pairs; Crawford et al. 2011). Most of its guano was removed between 1850 and 1950 (Urquhart and 

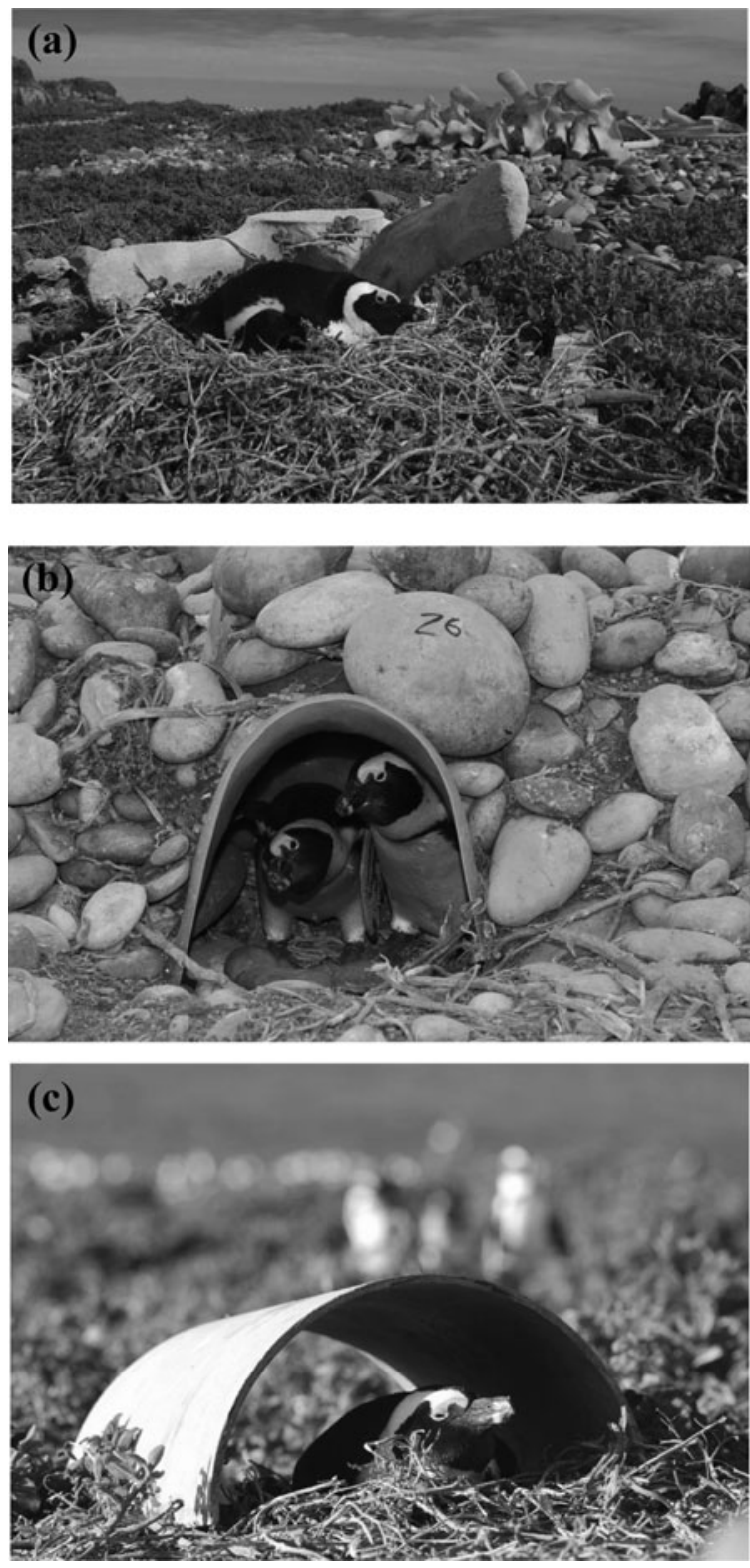

Figure 1. Pictures showing African Penguins breeding in (a) a natural surface nest, (b) an artificial fibreglass burrow, and (c) a 'pipe' nest on Bird Island, Nelson Mandela Bay, South Africa (photo credits: L. Edwards, B. Dilley).

Klages 1996). The island is flat and devoid of rocks or bushes and most penguins breed in surface nests (Figure 1a), where breeding success is generally poorer than in natural burrows (Seddon and van Heezik 1991). The island is permanently occupied by rangers from South African National Parks and receives regular visits by researchers and other groups, causing human disturbance. The Kelp Gull population in the Eastern Cape has increased since the 1970s, with currently 
43 pairs on Bird Island and another 189 pairs on neighbouring islands in 2005/06 (Crawford et al. 2009). The gull population was not disturbed in 2009, but in 2010 SANParks culled 62 gulls between February and June, as part of an active adaptive management intervention. As numbers of gulls increased again on the island after some months, another 116 were culled after the peak of the penguin breeding season in 2010. From then on, $<10$ gulls were seen at any given time during the 2011 penguin breeding season.

\section{Observations of gull predation}

Gulls often transport penguin eggs to a specific spot to consume them, forming middens of broken shells. Predated penguin eggs were counted daily during the penguin breeding season, along pathways that traverse roughly two thirds of the island's surface. Egg shells were squashed to avoid repeated counts of the same egg. The island is free of rats and other land predators that could target penguins, so penguin eggs found predated can be attributed only to Kelp Gulls. Comparisons of numbers of eggs found daily before (February-July 2009) and after (FebruaryJuly 2010) gull culling were made with a Mann-Whitney U-test. Predated chicks were excluded from the counts as they are often swallowed whole, leaving no remains.

Direct observations of gull behaviour were made from an $8 \mathrm{~m}$-high observation tower from which $>200$ occupied penguin nests could be observed. During 5-15 June 2009, 14-17 February 2010 (just prior to culling) and 24 June-7 July 2010 (after culling), one observer continuously recorded the number of gulls present, their activities, the number of attacks on penguin nests and the number of successful attacks. After a successful attack, gulls typically fly to consume their prey at a specific site. This behaviour attracted conspecifics, enhancing visibility. Observation sessions lasted $1-1.5$ hours, with usually one session in the morning and one in the afternoon. I compared morning and afternoon sessions in 2009 and 2010 with Generalised Linear Models (GLMs) including number of gulls (average and maximum), number of attacks, frequency of attack (number per hour) and success rate (per hour) as explanatory variables, the time of the session (morning/afternoon) as a dependent factor, and year as a random factor. I also compared the same parameters between the two sessions prior to culling (June 2009 and February 2010). As none of these tests was significant (see Results), I pooled the data and compared predation parameters before and after culling with GLMs. The very low number of gulls on the island in 2011 precluded such observations.

\section{Breeding success of artificial burrows and surface nests}

In January 2009, 150 artificial nests were set up on Bird Island by South African National Parks, in response to observations of gulls predating penguin eggs and chicks (SANParks unpublished data). These artificial fibreglass burrows, manufactured by the Dyer Island Conservation Trust (http:// www.dict.org.za/), are $60 \mathrm{~cm}$ long, $40 \mathrm{~cm}$ wide and $30 \mathrm{~cm}$ high, with an opening $25 \mathrm{~cm}$ wide and $28 \mathrm{~cm}$ high (Figure $\mathrm{rb}$ ). They have been used at several African Penguin colonies since the mid-20oos but no previous study has determined their effectiveness in increasing penguin breeding success. In 2010, sections of $\mathrm{c} .30 \mathrm{~cm}$ high and $70 \mathrm{~cm}$ long of cement pipes cut in half (hereafter referred to as 'pipe nests', Figure Ic) were added to the island, and 50 of these pipe nest were monitored in 2011. Both types of artificial nests were individually numbered with paint and their contents monitored weekly. In parallel, a sample of 70-100 randomly chosen natural surface nests were also monitored from 2009 to 2011 , after marking each with a numbered stone placed next to the nest.

African Penguins typically lay a clutch of two eggs (Hockey et al. 2005). Surface nests were selected during incubation and the nest contents (number of adults, eggs, chicks and size of chicks) were monitored every 7-10 days. If the eggs disappeared between successive checks, the nest was assumed to have failed at the incubation stage. After 6-8 weeks, the chicks leave their 
nests to join crèches (Seddon and van Heezik 1993) and are not reliably associated with individual nests. Hence, I assumed that a nest was successful (up to the post-guard stage) if the chicks were known to have reached eight weeks of age and the nest bowl was unoccupied. Each breeding attempt in a marked nest was considered independently, as most of the birds were not individually marked and more than one pair may occupy a nest site in a given season (pers. obs. on some marked pairs). Unfortunately, nest desertion due to disturbance by researchers was not systematically noted. However, African Penguins breeding on Bird Island are generally habituated to humans and only very rarely desert their nests temporarily after human disturbance. Nevertheless, their breeding success in this study might have been slightly underestimated due to a potential impact of researchers.

Breeding success was estimated using Mayfield's method (1961, 1975), with number of nest days calculated as the mid-point between nest visits. Nest survival probabilities were compared using survival models with the "survreg" function in R v2.12.o (R Development Core Team 2010), which treats the number of days to nest failure as the response variable. The maximum likelihood estimate of risk of failure $(F)$ per sampling interval was defined following Sherley et al. (2012):

$$
F=\exp (-\alpha-\beta \mathrm{x})
$$

where $\alpha$ and $\beta$ are the intercept and coefficients from the regression and $x$ is the value of the explanatory variable. Nest survival (S) at time $t$ was defined as

$$
S(t)=\exp (-\exp (F t))
$$

with $t$ the average time for incubation and fledging period ( 38 and 77 days respectively, Hockey et al. 2005). Breeding success was determined as (I) hatching success (probability of nests with at least one egg hatching), (2) fledging success (probability of nests with at least one chick reaching the post-guard stage), (3) overall breeding success (product of hatching success and fledging success). Breeding success was likely to be slightly over-estimated, as late chick mortality ( $>8$ weeks) due to disease, starvation or hypothermia is still possible. Upper and lower $95 \%$ confidence intervals $(\mathrm{CI})$ are

$$
\exp (-t(F-1.96 F / \sqrt{ } n)) \text { and } \exp (-t(F+1.96 F / \sqrt{ } \mathrm{n}))
$$

respectively, where $\mathrm{n}$ is the number of breeding attempt failures occurring during incubation or brooding. Nest survival was modelled with year and nest type as explanatory variables, and posthoc Tukey comparisons were made. Subsequently, as there was no difference in egg or chick survival between 2010 and 2011 (see results), these years were combined to estimate the survival of surface nests before and after culling, in comparison with fibreglass burrows as a control for environmental variability between years.

\section{Results}

Observations of gull predation

Prior to culling, 778 penguin eggs were found in gull eggshell middens over 173 days of observation ( $4.5 \pm 4.3$ eggs/day). In the same areas, these numbers decreased after culling to 121 predated eggs found over 62 days ( $1.9 \pm 3.3$ eggs/day, $U=23$ 060, $P<0.0001$ ). Direct observations of gull predation lasted 39 hours over 15 days before culling, and 25 hours over 14 days after culling. There was no significant difference in predation patterns between morning 
or afternoon sessions (average number of gulls: $F=1.4, P=0.26$, maximum number of gulls: $F=0.79, P=0.46$, total number of attacks witnessed: $F=0.28, P=0.75$, frequency of attacks $F=0.35, P=0.70$, success rate: $F=0.78, P=0.46$ ), suggesting a constant predation rate by gulls on penguin nests over the day. There was also no difference between observations prior to culling, in June 2009 and February 2010, with similar numbers of gulls present and similar frequency of attacks and success (Table 1 ; average number of gulls: $F=0.47, P=0.50$, maximum number of gulls: $F=1.2, P=0.20$, total no. of attacks witnessed: $F=0.41, P=0.53$, frequency of attacks $F=0.07, P=0.79$, success rate: $F=0.05, P=0.82$ ). However, there were significant differences in predation patterns before and after culling. After culling, fewer gulls were observed, the numbers of attacks and their frequency decreased, and none of the attacks was successful (Table 1).

\section{Breeding success}

From the 150 fibreglass burrows present on Bird Island, up to 257 breeding attempts have been recorded in a single breeding season (2009; Table 2). Some nests had up to four breeding attempts per season, suggesting that several pairs used the same artificial nest (Hockey et al. 2005). Surface nests on Bird Island are made of grass, and are ephemeral once unoccupied, as neighbours rapidly steal the nest material, hence a smaller number of repeated breeding attempts in surface nests. Fewer surface nests were monitored in 2010 and 2011 than in 2009 to limit disturbance, as the penguin colony was much reduced.

Hatching success did not improve in surface nests after the removal of predatory gulls $(z=0.234, P=0.82)$, but decreased in artificial burrows over the same period $(z=2.92$, $P<0.01$ ), which might suggest a potential deterioration of the environment during these years. However, chick survival significantly increased in surface nests after culling $(z=-3.37$, $P<$ o.001), resulting in breeding success in these nests twice as high after culling (Table 2 ).

Penguins that bred in fibreglass burrows consistently experienced lower hatching success than those breeding in both surface and pipe nests (Tables 2, 3). Chick survival, however, was similar in both types of artificial nests and consistently higher than in surface nests (Table 3), even after the removal of gulls. The combination of lower hatching success but higher fledging success in fibreglass burrows when compared to surface nests resulted in similar overall breeding success in both these nest types, although breeding success was slightly higher in surface nests after culling (Table 2). Finally in 2011 hatching success in pipe nests was as high as in surface nests, and fledging success as high as in fibreglass burrows (Table 3 ), which resulted in breeding success twice as high in pipe nests as both other nest types (Table 2).

Table 1. Level of gull predation on penguin nests from direct observations before and after culling some predatory gulls, with level of significance (nd: not determined), SE = standard error.

\begin{tabular}{|c|c|c|c|c|c|}
\hline & \multicolumn{2}{|l|}{ Before } & \multirow{2}{*}{$\frac{\text { After }}{\text { Jun-July } 2010}$} & \multirow[b]{2}{*}{$F$} & \multirow[b]{2}{*}{$P$} \\
\hline & Jun-o9 & Feb-10 & & & \\
\hline Duration of observations (h) & 33 & 6 & 25 & & nd \\
\hline Number of days of observations & 11 & 4 & 14 & & nd \\
\hline Average no. of gulls ( \pm SE) & $8.5 \pm 4.0$ & $8.7 \pm 2.8$ & $4.8 \pm 2.6$ & $13 \cdot 3$ & 0.001 \\
\hline Max. no. of gulls & 34 & 18 & 16 & 11.2 & 0.002 \\
\hline No. of attacks & 77 & 12 & 4 & $7 \cdot 7$ & 0.008 \\
\hline No. of successful attacks & 40 & 9 & $\mathrm{o}$ & & nd \\
\hline Success rate $(\%)$ & $52 \%$ & $75 \%$ & ०\% & 29.6 & 0.001 \\
\hline Frequency of attacks (per hour) & 1.9 & 2 & 0.16 & 8.2 & 0.006 \\
\hline
\end{tabular}


Table 2. Hatching, fledging and breeding success from natural surface nests and two types of artificial burrows (fibreglass and cement pipes) on Bird Island, Nelson Mandela Bay, South Africa, between January-August 2009, 2010 and 2011.

\begin{tabular}{|c|c|c|c|c|c|c|c|c|}
\hline & & \multicolumn{3}{|c|}{ Natural surface nests } & \multicolumn{3}{|c|}{ Fibreglass burrows } & \multirow{2}{*}{$\frac{\text { Cement pipes }}{2011}$} \\
\hline & & 2009 & 2010 & 2011 & 2009 & 2010 & 2011 & \\
\hline \multirow{5}{*}{ Incubating period } & $\mathrm{N}$ nests & 125 & 81 & 69 & 257 & 237 & 148 & 44 \\
\hline & Number of failures & 55 & 33 & 25 & 171 & 189 & 108 & 16 \\
\hline & Number of nest days & 3789.2 & $1977 \cdot 5$ & 1875 & 7547 & 6190 & 3694 & 1135 \\
\hline & Survival probability & 0.591 & 0.504 & $0.57^{0}$ & 0.416 & 0.319 & 0.356 & 0.571 \\
\hline & $95 \% \mathrm{CI}$ & $0.515-0.680$ & $0.399-0.637$ & $0.458-0.712$ & $0.365-0.475$ & $0.271-0.375$ & $0.293-0.433$ & $0.434^{-0.751}$ \\
\hline \multirow{5}{*}{ Chick rearing period } & $\mathrm{N}$ nests & 74 & 57 & 44 & 68 & 19 & 35 & 28 \\
\hline & Number of failures & 50 & 26 & 27 & 34 & 7 & 14 & 7 \\
\hline & Number of nest days & 2230 & 2749 & 1845.5 & 2817 & 665 & 2043 & 1691 \\
\hline & Survival probability & 0.196 & 0.447 & $0.35^{0}$ & 0.367 & 0.610 & 0.550 & 0.727 \\
\hline & $95 \% \mathrm{CI}$ & $0.124-0.307$ & $0.328-0.609$ & $0.236-0.520$ & $0.262-0.514$ & $0.422-0.879$ & $0.402-0.752$ & $0.574^{-0.921}$ \\
\hline \multirow{2}{*}{ Breeding success } & Survival probability & 0.116 & 0.225 & 0.200 & 0.153 & 0.195 & 0.196 & 0.415 \\
\hline & $95 \% \mathrm{CI}$ & $0.064-0.209$ & $0.131-0.388$ & $0.108-0.370$ & $0.096-0.244$ & $0.114-0.329$ & $0.118-0.326$ & $0.249-0.691$ \\
\hline
\end{tabular}


Table 3. Results of survival and Tukey post-hoc analyses comparing hatching and fledging success between years (2009-2011) and nest types (surface nests, fibreglass burrows and cement pipe nests).

\begin{tabular}{|c|c|c|c|c|c|c|c|}
\hline & & & Value & SE & $\mathrm{z}$ & $P$ & AIC \\
\hline & Hatching & intercept & $3 \cdot 74$ & 0.07 & 54.65 & $<0.0001$ & 6870 \\
\hline & & Year 2010 & -0.26 & 0.09 & -2.78 & $<0.01$ & \\
\hline & & Year2011 & -0.13 & 0.09 & -1.43 & 0.15 & \\
\hline & & Type open & 0.61 & 0.08 & $7 \cdot 54$ & $<0.0001$ & \\
\hline & & Type pipe & 0.61 & 0.26 & 2.38 & $<0.05$ & \\
\hline & Fledging & intercept & $4 \cdot 38$ & 0.15 & 29.59 & $<0.0001$ & $\mathbf{1 7 7 3}$ \\
\hline & & Year 2010 & 0.73 & 0.21 & 3.45 & $<0.001$ & \\
\hline & & Year 2011 & 0.48 & 0.19 & 2.49 & $<0.05$ & \\
\hline & & Type open & -0.49 & 0.20 & -2.4 & $<0.05$ & \\
\hline & & Type pipe & 0.63 & 0.42 & 1.49 & 0.14 & \\
\hline \multirow[t]{13}{*}{ TUKEY } & & & Estimate & Lower & Upper & $P$ & \\
\hline & Hatching & 2010-2009 & -0.262 & -0.482 & -0.041 & $*$ & \\
\hline & & 2011-2009 & -0.131 & -0.347 & 0.084 & ns & \\
\hline & & $2011-2010$ & 0.130 & -0.094 & 0.354 & ns & \\
\hline & & surface-fibreglass & 0.609 & 0.424 & 0.794 & * & \\
\hline & & pipe-fibreglass & 0.612 & 0.024 & 1.200 & $*$ & \\
\hline & & pipe-surface & 0.003 & -0.564 & 0.569 & ns & \\
\hline & Fledging & 2010-2009 & 0.730 & 0.235 & 1.226 & $*$ & \\
\hline & & 2011-2009 & 0.475 & 0.029 & 0.920 & $*$ & \\
\hline & & $2011-2010$ & -0.256 & -0.813 & 0.302 & ns & \\
\hline & & surface-fibreglass & -0.563 & -0.959 & -0.166 & * & \\
\hline & & pipe-fibreglass & 0.628 & -0.342 & 1.601 & ns & \\
\hline & & pipe-surface & 1.191 & 0.238 & 2.145 & * & \\
\hline
\end{tabular}

\section{Discussion}

Both types of artificial nests and the removal of predatory gulls increased African Penguin chick survival on Bird Island, although neither strategy improved hatching success, despite an observed decrease in numbers of penguin eggs found predated after culling. These results might suggest that a potentially important proportion of the penguin eggs counted as predated in this study before culling may have come from abandoned nests. Similarly, direct predation by Kelp Gulls on occupied Magellanic Penguin Spheniscus magellanicus nests in Argentina accounted for only a third of egg consumption, the rest coming from abandoned nests (Yorio and Boersma 1994). On the other hand, the concomitant decrease in hatching success in fibreglass burrows suggests a potential deterioration of the environment in 2010 and 2011, which is confirmed by a parallel study on breeding penguins' foraging effort (Pichegru et al. 2012). During years of low food availability, adult seabirds favour their own survival and increasingly abandon their current breeding attempt (e.g. Monaghan et al. 1992, Chaurand and Weimerskirch 1994). Poor environmental conditions in 2010 and 2011 could have masked a potential positive effect of gull removal on penguins' hatching success, as observed direct predation by gulls decreased after culling.

The culling of Kelp Gulls significantly increased penguin chick survival in surface nests. Chicks may be an easier target for gulls than incubated eggs underneath an adult penguin, as well as being potentially more nutritious than eggs. Similarly, heavier predation by Greater Black-backed Gulls Larus marinus on Eider Duck Somateria mollissima chicks in Quebec, Canada, rather than on eggs, led to an almost complete breeding failure, despite a very high hatching success of $>80 \%$ (Donehower and Bird 2008). Seabird parental investment in chicks is generally higher than in eggs, and African Penguins are less likely to reattempt breeding after a failure at the chick-rearing stage than after a failure at the incubating stage (Hockey et al. 2005). Increasing chick survival 
can therefore have an important impact on penguins' final reproductive output, even more so during years of low food availability. Indeed, when food abundance decreases, seabird parents typically reduce their nest attendance to increase their foraging trip duration (Cairns 1987), leaving unattended offspring more vulnerable to predators. Moreover, predation can increase on individuals weakened by scarcity of food (Swennen 1989). Finally, high nesting densities in seabird colonies enhance nest defence, restricting predation to peripheral nests (e.g. Frere et al. 1992), and declining colonies suffer greater predation rates (Gilchrist 1999). This Allee effect is likely to accelerate the decline of already vulnerable populations (Stephens and Sutherland 1999). Therefore, removal of predators is likely to be even more effective in enhancing seabird productivity during years of food stress.

Although gull-culling experiments sometimes showed contrasting results depending on the species targeted (see Wanless et al. 1996, Finney et al. 2003), they confirm that in order to be effective, culling should be continued over several years (Guillemette and Brousseau 2001, Sanz-Aguilar et al. 2009). Gull predation can return to pre-culling levels the following year (Guillemette and Brousseau 2001), as gull populations are regulated by density-dependent effects (Duncan 1978). Gulls are highly territorial, and will prevent other conspecifics from foraging on their part of the seabird colony (Spears 1993) so new recruits will constantly fill territories opened by culling (Duncan 1978, Guillemette and Brousseau 2001). Moreover, gulls targeting seabird chicks tend to be high-quality individuals that produce more fledglings per pair and faster growing chicks than other pairs (Watanuki 1992, Spears 1993), so there could be a positive selection to maintain that behaviour in a population. Similarly, Kelp Gull abundance on Bird Island increased a few months after the first culling session. Eliminating predatory gulls therefore requires ongoing management. In addition, systems where predators are removed should be monitored extremely carefully to detect potential effects of culling on the targeted predator population on a local and metapopulation scale, but also on the system itself. Predators usually target sick and/or weak individuals (Genovart et al. 2010), so systems where natural predators are removed can be more sensitive to disease outbreaks (e.g. Steen et al. 2005).

As an alternative to culling, artificial nests also improved African Penguin chick survival on Bird Island, although the success of such nests depended on their design. The consistently poor hatching success in fibreglass burrows revealed that these nests are far from mimicking conditions in natural burrows, which provide the birds with relatively constant humidity and temperature, and protect them from the wind (Frost et al. 1976). Temperatures in fibreglass burrows are probably too high to allow most eggs to hatch, as was suggested by extreme temperatures $\left(>57^{\circ} \mathrm{C}\right)$ recorded in artificial nest boxes on Robben Island, another African Penguin colony on the west coast of South Africa (Griffin 2005). Simple aerated shelters made of cement pipes were more effective than fibreglass burrows in increasing penguin breeding success, although these results might be slightly overestimated due to a limited sample size, as well as the absence of gulls from the study site when this second type of nests were added: such nests might not protect penguins from gull predation as much as fibreglass burrows, and further studies might be necessary to answer that question. In Namibia, similar positive results were obtained from artificial nests made out of plastic bins cut in half and slightly buried in the ground (Kemper et al. 2007). The authors suggested that plastic could prevent infestation by ticks, compared to nests made of rocks or cement. Therefore, the success of pipe nests needs to be confirmed over several years. Nevertheless, the high chick survival from both types of artificial nest suggests that they consistently provide shelter against extreme weather events, to which surface nests remain exposed without predators. Similar results were found on Robben Island, where chick survival in artificial nests was also higher than any other nest type (Sherley et al. in press). Mortality of small African Penguin chicks can be very high during severe rains (up to $80 \%$; Randall et al. 1986). Climate changes increase the frequency of extreme weather events (Parmesan et al. 2000), which can have dramatic events on some populations (McKechnie and Wolf 2010). In this context, appropriately designed artificial nests seem to provide the best solution to sustainably increase African Penguin breeding success. 
However, where the use of such nests is logistically unrealistic, such as where the topography of the colony prevents it, culling predatory gulls can rapidly increase penguins' reproductive output. The consistently low breeding success on Bird Island during this study (c. o.2) when compared to the breeding success of penguins from the west coast of South Africa in the mid-1990s (0.486; Wolfaardt et al. 2008), emphasizes the poor environmental conditions prevailing at this colony, largely as a result of anthropogenic influence (Crawford et al. 2011). Although Kelp Gulls are natural predators of African Penguins and other seabirds, their impacts have been distorted through human activities. Kelp Gull populations in South Africa are presumably above historical limits (Steele and Hockey 1990), benefiting from human-induced food subsidies (Crawford et al. 2009). In such disturbed systems, human intervention is justified to assist the endangered species. Controlling gull numbers on breeding islands may also benefit non-burrowing seabirds, as Kelp Gulls can also target eggs and small chicks of Cape Cormorant Phalacrocorax capensis, Cape Gannet Morus capensis and Roseate Tern Sterna dougallii (Brooke and Cooper 1979, Steele and Hockey 1990), all of which are now of conservation concern (BirdLife International 2011). The recent collapse in African Penguin numbers requires urgent management actions (Crawford et al. 2011). The African Penguin Biodiversity Management Plan (Waller and Shaw 2010) recommends the introduction of artificial burrows in order to increase suitable breeding habitat for penguins as well as to limit gull predation. This study revealed that the design of artificial nests must be carefully thought through before installing these nests in penguin colonies, in order to be successful. The Biodiversity Management Plan also suggested pricking gulls' eggs in order to control their population size and level of predation, but this study shows that removing Kelp Gulls from penguin colonies is probably a much more efficient way of increasing penguin production. However, the present results emphasise the need for ongoing management and largescale coordination of such a strategy.

To significantly improve the conservation status of African Penguins, such conservation strategies should be concomitant with limiting oil spills and spatial management of fishing effort to increase food availability in their limited foraging range during the breeding season (Crawford et al. 2011, Pichegru et al. 2012).

\section{Acknowledgements}

This work is mainly the fruit of weeks of patient data collection by the marine rangers of Addo Elephant National Park and I am indebted to them. I am also grateful to V. Lategan, S. Jones, H. Visser and N. Steele for their hours of observations. Finally, I warmly thank A. Gaylard, P. G. Ryan, P. Yorio, C. Loiseau, R. Sherley and R. van Eeden for their help at different stages of this manuscript. I thank Popi and another anonymous referee for their useful comments. During the study, LP was financed by "the African Penguin Species Champion" project of the Charles van der Merwe Trust.

\section{References}

Bertellotti, M., Yorio, P., Blanco, G. and Giaccardi, M. (2001) Use of tips by nesting Kelp Gulls at a growing colony in Patagonia. J. Field Ornithol. 73: 338-348.

BirdLife International (2011) IUCN Red List for birds. http://www.birdlife.org.

Blokpoel, H. and Spaans, A. L. (1991) Introductory remarks: superabundance in gulls: causes, problems and solutions. Acta
XX Congressus Internationalis Ornithologici, pp $2361-2364$.

Brooke, R. K. and Cooper, J. (1979) What is the feeding niche of the Kelp Gull in South Africa? Cormorant 7: 27-29.

Cairns, D. K. (1987) Seabirds as indicators of marine food supplies. Biol. Oceano. 5: 261-271. 
Chaurand, T. and Weimerskirch, H. (1994) Incubation routine, body mass regulation, and egg neglect in the blue petrel Halobaena caerulea. Ibis 136: 285-290.

Cooper, J. (1974) The predators of the jackass penguin Spheniscus demersus. Bull. Brit. Ornithol. Club 94: 21-24.

Crawford, R. J. M., Williams, A. J., Hofmeyr, J. H., Klages, N. T. W., Randall, R. M., Cooper, J., Dyer, B. M. and Chesselet, Y. (1995) Trends of African Penguin Spheniscus demersus populations in the 2oth century. S. Afr. J. Mar. Sci. 16: 101-118.

Crawford, R. J. M., Whittington, P. A., Martin, P. A., Tree, A. J. and Makhado, A. B. (2009) Population trends of seabirds breeding in South Africa's Eastern Cape and the possible influence of anthropogenic and environmental change. Mar. Ornithol. 37: 159-174.

Crawford, R. J. M., Altwegg, R., Barham, B. J., Barham, P. J., Durant, J. M., Dyer, B. M., Makhado, A. B., Pichegru, L., Ryan, P. G., Underhill, L. G., Upfold, L., Visagie, J., Waller, L. J. and Whittington, P. A. (2011) Collapse of South Africa's penguins in the early 21st century: a consideration of food availability. Afr. J. Mar. Sci. 33: 139-156.

Demongin, L., Poisbleau, M., Strange, I. J. and Quillfeldt, P. (2010) Effects of severe rains on the mortality of southern rockhopper penguin Eudyptes chrysocome chicks and its impact on breeding success. Ornitol. Neotrop. 21: 439-443.

Dickman, C. R. (2008) Indirect interactions and conservation in human-modified environments. Anim. Conserv. 11: 11-12.

Donehower, C. E. and Bird, D. M. (2008) Gull predation and breeding success of common eiders on Stratton Island, Maine. Waterbirds 31: 454-462.

Duncan, N. (1978) The effects of culling herring gulls (Larus argentatus) on recruitment and population dynamics. J. Appl. Ecol. 15: 697-713.

Finney, S. M., Harris, M. P., Keller, L. F., Elston, D. A., Monaghan, P. and Wanless, S. (2003) Reducing the density of breeding gulls influences the pattern of recruitment of immature Atlantic puffins Fratercula arctica to a breeding colony. J. Appl. Ecol. 40: $545-552$.
Frere, E., Gandini, P. and Boersma, P. D. (1992) Effects of nest type and location on reproductive success of the magellanic penguin Spheniscus magellanicus. Mar. Ornithol. 20: 1-6.

Frost, P. G. H., Siegfried, W. R. and Burger, A. E. (1976) Behavioural adaptations of the jackass penguin Spheniscus demersus to a hot, arid environment. J. Zool. Lond. 179: 165-187.

Genovart, M., Negre, N., Tavecchia, G., Bistuer, A., Parpal, L. and Oro, D. (2010) The young, the weak and the sick: evidence of natural selection by predation. PLoS ONE 5: e9774.

Gilchrist, H. G. (1999) Declining thick-billed murre Uria lomvia colonies experience higher predation rates, an inter-colony comparison. Biol. Conserv. 87: 21-29.

Griffin, J. (2005) Penguins feel the heat. Quest 1: $16-17$.

Guillemette, M. and Brousseau, P. (2001) Does culling predatory gulls enhance the productivity of breeding common terns? J. Appl. Ecol. 38: 1-8.

Harris, M. P. and Wanless, S. (1997) The effect of removing large numbers of gulls Larus spp. on an island population of oystercatchers Haematopus ostralegus: implications for management. Biol. Conserv. 82: 167-171.

Hockey, P. A. R., Dean, W. R. J. and Ryan, P. G. (2005) Roberts' birds of Southern Africa. Seventh edition. Cape Town: John Voelcker Bird Book Fund.

Kemper, J., Underhill, L. G. and Roux, J.-P. (2007) Artificial burrows for African Penguins on Halifax Island, Namibia: do they improve breeding success?, in: Kirkman, S.P. (ed), Final report of the BCLME (Benguela Current Large Marine Ecosystem) project on top predators as biological indicators of ecosystem change in the BCLME. Avian Demography Unit, Cape Town, South Africa, pp 101-106.

Lisnizer, N., Garcia-Borboroglu, P. and Yorio, P. (2011) Spatial and temporal variations in Kelp Gull population trends in northern Patagonia, Argentina. Emu 111: 259-267.

McKechnie, A. E. and Wolf, B. O. (2010) Climate change increases the likelihood of catastrophic avian mortality events 
during extreme heat waves. Biol. Lett. 6: 253-256.

Mayfield, H. (1961) Nesting success calculated from exposure. Wilson Bull. 73: 255-261.

Mayfield, H. (1975) Suggestions for calculating nest success. Wilson Bull. 87: 456-466.

Monaghan, P., Uttley, J. D. and Burns, M. D. (1992) Effects of changes in food availability on reproductive effort in Arctic terns. Ardea 80: 71-81.

Oro, D. and Martínez-Abraín, A. (2007) Deconstructing myths on large gulls and their impact on threatened sympatric waterbirds. Anim. Conserv. 10: 117-126.

Parmesan, C., Root, T. L. and Willig, M. R. (2000) Impacts of extreme weather and climate on terrestrial biota. Bull. Amer. Meteorol. Soc. 81: 443-450.

Perriman, L. and Steen, H. (2000) Blue penguin (Eudyptula minor) nest distribution and breeding success on Otago Peninsula, 1992-1998. New Zeal. J. Zool. 27: 269-275.

Pichegru, L., Grémillet, D., Crawford, R. J. M. and Ryan, P. G. (2010) Marine no-take zone rapidly benefit threatened penguin. Biol. Lett. 6: 498-501.

Pichegru, L., Ryan, P. G., van Eeden, R., Reid, T., Grémillet, D. and Wanless, R. (2012) Industrial fishing, no-take zones and endangered penguins. Biol. Conserv. doi:10.1016/j.biocon.2011.12.013.

R Development Core Team (2010) R: A language and environment for statistical computing. Vienna, Austria: R Foundation for Statistical Computing. http://www. R-project.org/.

Randall, R. M., Randall, B. M. and Erasmus, T. (1986) Rain-related breeding failures in Jackass penguins. Le Gerfaut 76: 281-288.

Renner, M. and Davis, L. S. (2001) Survival analysis of Little Penguin Eudyptes minor chicks on Motuara Island, New Zealand. Ibis 143: 369-379.

Ropert-Coudert, Y., Cannell, B. and Kato, A. (2004) Temperature inside nest boxes of little penguins. Wildl. Soc. Bull. 32: 177-182.

Sanz-Aguilar, A., Martínez-Abraín, A., Tavecchia, G., Minguez, E. and Oro, D. (2009) Evidence-based culling of a facultative predator: efficacy and efficiency components. Biol. Conserv. 142: 424-431.
Seddon, P. J. and Davis, L. S. (1989) Nest site selection by yellow-eyed penguins. Condor 91: 653-659.

Seddon, P. J. and van Heezik, Y. M. (1991) Effects of hatching order, sibling asymmetries, and nest site on survival analysis of jackass penguin chicks. Auk 108: 548-555.

Seddon, P. J. and van Heezik, Y. M. (1993) Chick creching and intraspecific aggression in the Jackass Penguin (Spheniscus demersus). J. Field Ornithol. 64: 90-95.

Sherley, R., Ludynia, K., Underhill, L. G., Jones, R. and Kemper, J. (2012) Storms and heat limit the nest success of Bank Cormorants: implications of future climate change for a surface-nesting seabird in southern Africa. J. Ornithol. doi: 10.1007/s10336011-0760-8

Sherley, R., Barham, B., Barham, P., Leshoro, M. and Underhill, L. (in press) Artificial nests enhance the breeding productivity of African Penguins (Spheniscus demersus) on Robben Island, South Africa. Emu.

Spears, L. B. (1993) Dynamics and effect of Western gulls feeding in a colony of guillemots and Brandt's cormorants. J. Anim. Ecol. 62: 399-414.

Steele, W. K. and Hockey, P.A.R. (1990) Population size, distribution and dispersal of Kelp Gulls in the southwestern Cape, South Africa. Ostrich 61: 97-106.

Steen, M., Olsson, I.-M. and Broman, E. (2005) Diseases in a moose population subjected to low predation. Alces 41: 37-48.

Stephens, P. A. and Sutherland, W. J. (1999) Consequences of the Allee effect for behaviour, ecology and conservation. TREE 14: 401-405.

Sutherland, W. J., Pullin, A. S., Dolman, P. M. and Knight, T. M. (2004) The need for evidence-based conservation. TREE 19: 305-308.

Swennen, C. (1989) Gull predation upon eider Somateria mollissima ducklings: destruction or elimination of the unfit? Ardea 77: 21-45.

Urquhart, C. and Klages, N. (1996) East of the isles. The story of the bird islands of Algoa Bay, South Africa. Bridgemeade, South Africa: Bluecliff Publishing.

Waller, L. J. and Shaw, K., eds. (2010) Biodiversity management plan for African Penguins. Proceedings of the African 
Penguin BMP-S workshop, Arniston, 2628th October 2010, South Africa.

Wanless, S., Harris, M. P., Calladine, J. and Rothery, P. (1996) Modelling responses of herring gull and lesser black-backed gull populations to reduction of reproductive output: implications for control measures. J. Appl. Ecol. 33: 1420-1432.

Watanuki, Y. (1992) Individual diet difference, parental care and reproductive success in slaty-backed gulls. Condor 94: 159-171.

Wolfaardt, A. C., Underhill, L. G., Nel, D. C., Williams, A. J. and Visagie, J. (2008) Breeding success of African Penguins Spheniscus demersus at Dassen Island, especially after oiling following the Apollo Sea spill. Afr. J. Mar. Sci. 30: 565-580.

Yodzis, P. (1998) Local trophodynamics and the interaction of marine mammals and fisheries in the Benguela ecosystem. J. Anim. Ecol. 67: 635-658.
Yorio, P. and Boersma, P. D. (1994) Consequences of nest desertion and inattendance for magellanic penguin hatching success. Auk 111: 215-218.

Yorio, P. and Caille, G. (2004) Fish waste as an alternative resource for gulls along the Patagonian coast: availability, use, and potential consequences. Mar. Poll. Bull. 48: $778-783$.

Yorio, P. and Quintana, F. (1997) Predation by Kelp Gulls Larus dominicanus at a mixed-species colony of royal and cayenne terns Sterna maxima and $S$. eurygnatha in Patagonia. Ibis 139: 536-541.

Yorio, P., Bertellotti, M., Gandini, P. and Frere, E. (1998) Kelp Gulls Larus dominicanus breeding on the Argentine coast: population status and relationship with coastal management and conservation. Mar. Ornithol. 26: 11-18.

\section{LORIEN PICHEGRU}

Percy FitzPatrick Institute, DST/NRF Centre of Excellence, University of Cape Town, 7701 Rondebosch, Cape Town, South Africa.

${ }^{*}$ Author for correspondence; email: lorien.pichegru@uct.ac.za

Received 19 October 2011; revision accepted 27 January 2012; Published online 3 April 2012 